\title{
El diseño de la realidad televisiva en el documental de naturaleza: El Hombre y la Tierra. Serie Venezo- lana (Félix Rodríguez de la Fuente, 1974)
}

\author{
José CABEza SAN DEOGRACIAS \\ Universidad Rey Juan Carlos \\ jose.cabeza@urjc.es \\ Salvador GóMEz GARCÍA \\ CES Felipe II - UCM \\ salvador.gomez@ajz.ucm.es
}

Recibido: 28/07/2011

Aceptado: 30/01/2012

\section{Resumen}

Este artículo analiza las referencias audiovisuales que influyeron en la creación de El Hombre y la Tierra (Félix Rodríguez de la Fuente, 1974-1981), y también el trabajo de montaje que se llevó a cabo con el jaguar en los 18 episodios de la Serie Venezolana. El estudio, análisis y clasificación de todas las imágenes del depredador demuestran la manipulación del montaje para obtener un programa de televisión entretenido y, a la vez, informativo. A través de este trabajo, Rodríguez de la Fuente comprobó que la reconstrucción documental era la mejor forma de reproducir la vida salvaje de los animales y lograr un producto audiovisual atractivo y veraz.

Palabras clave: Documental de naturaleza, El Hombre y la Tierra, Documental científico, programación televisiva, infotainment, divulgación

\section{The Design of Television Reality in Nature Documentary: El Hombre y la Tierra. Serie Venezolana (Félix Rodríguez de la Fuente, 1974)}

\begin{abstract}
This article will analyze both the audiovisual references that affect directly in the conception of documentary serie El Hombre y la Tierra (Félix Rodríguez de la Fuente, 1974-1981) and the film editing that have been done in Jaguar scenes along the 18 episodes in the Serie Venezolana. Study, analysis and classification of all predator images will prove the manipulative use of film editing in order to get a amusing and successful tv programme, but also informative. Through these episodes, Rodríguez de la Fuente discovered that reconstruction documentary was the best way to record wild animals life and get a fine and truly audiovisual product with it.

Keywords: Nature documentary, El Hombre y la Tierra, Scientific documentary, TV program, infotainment, scientific dissemination

\section{Referencia normalizada}

CABEZA, José y GÓMEZ, Salvador (2012): "El diseño de la realidad televisiva en el documental de naturaleza: El Hombre y la Tierra. Serie Venezolana (Félix Rodríguez de la Fuente, 1974)". Estudios sobre el mensaje periodístico. Vol. 18, núm. 1, págs.: 275-291. Madrid, Servicio de Publicaciones de la Universidad Complutense.
\end{abstract}

Sumario: 1. Introducción y metodología. 2. El modelo Cousteau. 3. National Geographic y Walt Disney: necesariamente entretenidos. 4. El montaje del jaguar: creando la realidad. 5. Conclusión y reflexión. 6. Referencias bibliográficas.

\section{Introducción y metodología}

La Serie Venezolana (1974, 18 capítulos) es la primera de las tres partes en las que se divide El Hombre y la Tierra. Después vendría la Serie Ibérica (1975-79, 91 capítu- 
los) y, por último, la Serie Canadiense (1979-1981, 14 capítulos). Esta primera producción apenas representa un $14.6 \%$ del total de capítulos de la serie, pero fueron los primeros y, por lo tanto, decisivos para descubrir y delimitar el estilo de producción, los recursos narrativos y el tono del programa que se quería crear. Venezuela significó el choque con la realidad de la creación de documentales de naturaleza en dos sentidos: cómo filmar mejor la vida salvaje de los animales (producción y rodaje) y cómo convertir esa vida en un producto televisivo (postproducción).

La bibliografía existente sobre El Hombre y la Tierra y su autor no es escasa, pero sí irregular, y se puede clasificar en tres diferentes grupos temáticos. El primer grupo, el más numeroso, lo constituyen las biografías sobre Félix Rodríguez de la Fuente. Entre las 6 obras que hay editadas destaca, por pionero, el trabajo de Joaquín ARAUJo: Félix Rodríguez de la Fuente. La voz de la naturaleza (1990) o Félix Rodríguez de la Fuente. El "amigo de los animales", que nos mostró los secretos de la naturaleza (1991). Aunque también sobresale la biografía más reciente de todas: Félix Rodríguez de la Fuente. Su vida, mensaje de futuro, escrita por Benigno VARILLAS. Este trabajo está publicado con la autorización de la Fundación Félix Rodríguez de la Fuente y es, sin duda, la biografía más completa y rigurosa en cuanto al trabajo con las fuentes y a la abundancia de datos que aporta. En un segundo grupo está el trabajo de Rodríguez Jiménez en Así se hizo. 1, El hombre y la tierra (2006), que resulta concreto, pero muy alejado de una línea científica al desenvolverse entre el testimonio y la insidia para analizar el trabajo y el comportamiento de Rodríguez de la Fuente en las diferentes fases de pre-producción o producción de la serie El Hombre y la Tierra. En tercer y último lugar está la obra científica más específica, exhaustiva y amplia: $E l$ documental de divulgación científica sobre la naturaleza: técnicas narrativo-dramáticas y retóricas empleadas por Félix Rodríguez de la Fuente en El Hombre y la Tierra. Su autora, Miriam SALCEDO DE PRADO, se centra en una extensa contextualización del documental de divulgación científica sobre naturaleza, incluye un pertinente acercamiento biográfico a la figura de Rodríguez de la Fuente y, lo más importante, analiza la producción de El Hombre y la Tierra así como los recursos narrativos y las técnicas retóricas que utiliza el autor para construir los episodios de la serie.

Para centrar esta investigación, este artículo aporta análisis y reflexiones sobre un tema fundamental para entender el éxito, y también la polémica, de la serie de El Hombre y la Tierra: la reconstrucción documental. El objetivo de Rodríguez de la Fuente era utilizar sus documentales para educar al mayor número posible de espectadores sobre cómo era de verdad el mundo animal y la relación que el hombre tenía con la naturaleza, aunque también era consciente de que creaba un producto para la televisión y que necesariamente tenía que ser divertido para conseguir consolidar la serie ante un público no especializado en contenidos científicos. De ahí la necesidad de diseñar, es decir, planificar o proyectar por adelantado la realidad que iban a ver los espectadores en el programa, esa realidad televisiva tendría que ser verdad, pero también divertida, lo cual exigía una selección de momentos significativos en la vida de los animales que cumpliera con ambos objetivos, sin que ninguno de los dos quedase muy reducido o eclipsado por el otro. Si esos instantes claves de la vida del animal no podían obtenerse directamente filmando la realidad habría que construirlos en la sala de montaje. 
En Venezuela se filmaron 80 horas de imágenes, de las cuales se extrajeron 9 horas útiles para emisión: 18 capítulos, con una duración de 26 minutos cada uno, que fueron emitidos por primera vez por TVE-1 entre el 4 de marzo de 1974 y el 12 de agosto de 1974. En toda la Serie Venezolana únicamente el jaguar o tigre americano aparece representado en 9 capítulos de los 18 que se filman: un 50\%. Por su importancia interesa analizar la representación audiovisual que se hizo de este depredador, ya que el trabajo en postproducción que se llevó a cabo con él sirvió de modelo de las pautas de montaje y de reconstrucción documental utilizadas en las dos series posteriores.

Se han analizado todas las imágenes del jaguar que aparecen en los 18 capítulos de la Serie Venezolana y se han clasifican por acciones en 4 grupos diferentes. Primero, en el apartado Ver se agrupan los momentos en los que el jaguar está andando, descansando o corriendo. En Luchar están los enfrentamientos por comida, supervivencia o época de celo. En Comer se recogen sólo un tipo de acciones: cuando el jaguar está devorando a sus presas. En Cazar se clasifican todos los intentos de caza por parte del jaguar, ya sean fallidos o exitosos. Y, por último, está Hacer, la categoría más general de todas y que incluye una gran diversidad de actividades que no coinciden con ninguna de las anteriores y aparecen, por lo general, de forma aislada como retozar, beber, manipular objetos, mordiquear un palo...

El jaguar aparece en 41 ocasiones en los 18 capítulos de la serie Venezolana, sin embargo sólo se han clasificado 32 acciones dramáticas concretas y específicas. El resto son acciones menores que quedan englobadas por otras más importantes, por ejemplo antes de cazar vemos al jaguar acechando, pero no se contabiliza como Ver, porque se da mayor importancia a las acciones que generan algo similar a nudos de acción, es decir, bloques narrativos con su propio planteamiento, nudo y desenlace, unidos por un criterio diegético, que trasciende las divisiones de tiempo y espacio (SÁNCHEZ-EsCALONILla, 2004: 152). A veces esos nudos de acción pueden ser muy breves (simplemente se presenta al jaguar como depredador y se le ve andar) o más extensos (una escena de caza o una persecución).

Este estudio prueba que Rodríguez de la Fuente comprobó en la filmación y posterior montaje de los capítulos rodados en Venezuela que la reconstrucción documental, aunque significara dirigir y manipular animales y entornos naturales, era la única forma de satisfacer, en aquella época y con los medios de los que disponía, la exigencia de mostrar la vida salvaje de los animales y de obtener al mismo tiempo éxito comercial en televisión.

\section{EI modelo Cousteau}

Jacques-Yves Cousteau consigue el Grand Prize en el festival de Cannes en 1956 con su primer documental cinematográfico: Le Monde du silence. Después de este éxito, y de filmar algunas películas cinematográficas más, Cousteau crea la serie documental televisiva The undersea world of Jacques Costeau (1968-1976), que fue muy bien recibida por crítica y público, y no sólo por la calidad de las imágenes, sino también por la capacidad innovadora de su formato: no había un narrador, sino dos, y uno de ellos era el propio Cousteau. Narrativamente, Rodríguez de la Fuente tiene muy en cuenta el modelo del creador francés, en el que el naturalista no sólo cuenta la histo- 
ria, sino que también es parte de ella y, ocasionalmente, la crea. En el viaje a Venezuela queda patente el "modelo Costeau" (Araujo, 1990: 134): el explorador y su equipo están omnipresentes y relatan lo que les sucede en primera persona.

En el episodio Los Yanomamos, pueblo de la selva, Rodríguez de la Fuente aparece a los mandos de una avioneta (min. 4) para dar la impresión de que él mismo está pilotando, aunque ni sabía hacerlo ni tampoco le gustaban los aviones. En En busca de los indios del Orinoco, Rodríguez de la Fuente empuja una canoa o coge unos prismáticos para ver los pájaros en el Orinoco (min. 5 y 6). Y cuando llegan a un poblado, él es el primero que desembarca (min. 24). En Un campamento en la selva virgen sucede lo mismo: llegan a una aldea y él camina el primero (min. 6). En La montaña sagrada se le ve montar en un helicoptero y escalar una montaña. Sin embargo, más allá de la presencia visual del naturalista en prácticamente todos los episodios, Rodríguez de la Fuente también crea y participa de las tramas al descubrir al público cómo es la vida de los indígenas, interactuar con los animales o intentar explicar la relación entre el hombre y la naturaleza o entre los indígenas y el mundo occidental.

De hecho, la única forma de lograr todo el material que se consiguió en el plazo de 2 meses que duró la expedición a Venezuela consiste en tener algo parecido a un guión, una previsión de qué va a suceder exactamente y, sobre todo, de cuándo va a suceder para poder organizar la producción y filmarlo. Sólo así se tiene cierta seguridad de obtener capítulos mínimamente estructurados y diferenciados del anterior por un contenido específico. No había tiempo para esperar y tener la fortuna de que la vida en la selva -la parte de la vida en la selva más cinematográfica- simplemente sucediera ante las cámaras. El equipo de El Hombre y la Tierra a veces debía provocar las situaciones para poder rodarlas. En El pueblo bravo se dedica la mitad del episodio (min 12-25) a contemplar los preparativos de una ceremonia y los efectos que tiene en los indígenas la inhalación de una droga llamada yopo. Rodríguez de la Fuente reconoce que están haciendo una fiesta "para las cámaras de televisión". Insiste en ello una segunda vez: " [...] Esta fiesta que, en realidad, era una fiesta para el cine, poco a poco se va transformando". Algo parecido, aunque de forma más limitada, ocurre con la grabación de ciertos animales, como la anaconda. Antes del viaje, en el zoo de Madrid, Rodríguez de la Fuente se entrena para aprender a apresar bien a una anaconda y poder realizar la acción sin peligro y de forma hábil en Venezuela (Pou, 1995: 181), donde sabe que se va a encontrar con este ofidio aislado en grandes charcos de barro como consecuencia de la ausencia de lluvias. Si el objetivo es filmar a una anaconda, se puede mostrar al animal mientras se desliza por el fango o por la tierra o bien se puede optar por una representación en acción, luchando por liberarse de las manos de un hombre: la forma más espectacular, por la inclusión de una acción vistosa y poco habitual, es obviamente la segunda. Y sería muy difícil conseguir una acción similar, en la que se viera la fiereza del animal y su capacidad para abrazar a una presa, sino estuviera en algún sentido fabricada. La acción es muy valiosa en términos de entretenimiento, pero también resulta científicamente relevante.

Indudablemente, el trabajo con los animales es de mayor complejidad y más delicado que el que se lleva a cabo con los indios Yanomamos, a los que era suficiente con invitarles a que hicieran una representación de su cultura, pero eso no impide que en 
la Serie Venezolana haya todo un capítulo en el que Rodríguez de la Fuente no influye en la historia, sino que la crea completamente. Es el caso del episodio titulado Mi amiga la nutria (Ver Cuadro 1)

Cuadro 1. Escenas de Mi amiga la nutria

\begin{tabular}{|l|l|}
\hline \multicolumn{2}{|l|}{ Mi amiga la nutria } \\
\hline Min. 1-3 & Presentación del caso de la nutria \\
\hline Min. 3-7 & Rodríguez de la Fuente da de comer a la nutria, la pasea en barca, juega con ella... 5 -8-1974 \\
\hline Min. 7 & El equipo de El Hombre y la Tierra le hace un cajón a la nutria \\
\hline Min. 7-8 & El equipo de El Hombre y la Tierra viaja y se llevan la nutria con ellos \\
\hline Min. 10 & Rodríguez de la Fuente llega a la mision con la nutria en brazos \\
\hline Min. 11 & Rodríguez de la Fuente y unos niños corren junto a la nutria \\
\hline Min. 20 & La nutria se mete en la tienda de campaña con el equipo de El Hombre y la Tierra \\
\hline Min. 21 & $\begin{array}{c}\text { Rodríguez de la Fuente lleva a la nutria al mar y ésta se zambulle en las aguas ma- } \\
\text { rinas }\end{array}$ \\
\hline Min. 22 & La nutria sigue a Rodríguez de la Fuente cuando sale de su habitación \\
\hline Min. 23 & Rodríguez de la Fuente y la nutria viajan juntos en un barco \\
\hline Min. 23-25 & Rodríguez de la Fuente y la nutria nadan juntos en el mar \\
\hline
\end{tabular}

Fuente: Elaboración propia. El hombre y la Tierra. Serie Venezolana

Sin la relación dirigida entre el naturalista y la nutria y la iniciativa del equipo para tomar decisiones sobre qué hacer con el animal este capítulo no existiría. Como se ve, el aquí llamado modelo Cousteau permite dotar de contenido a capítulos aunque las imágenes o acciones que se hayan filmado no sean a priori lo suficientemente buenas o espectaculares para llamar la atención por sí mismas. Cada episodio de The Undersea world of Jacques Cousteau, que tenía una duración aproximada de 51 minutos, el doble que uno de El Hombre y la Tierra, requería un descomunal trabajo de montaje para componer las imágenes y conseguir una buena película, que no siempre existía cuando se rodaba directamente en el mar por la falta de "cooperación" de los animales salvajes y la naturaleza inestable de las condiciones marítimas. Sólo el trabajo de preparación del corte final de la película, una vez filmada, podía extenderse más de 10 semanas para cada capítulo (AITKEN, 2006: 254).

De ahí la importancia de tener un protagonista fiable que sea parte de la historia, porque eso permite dominar la secuencia de acontecimientos y prever, y por lo tanto filmar sin problemas, lo que va a suceder. En la medida en que él interviene, reduce la incertidumbre de la filmación y asegura un desarrollo narrativo independientemente del éxito o fracaso en la búsqueda de los animales y de las imágenes de impacto. La reducción del tiempo, y por lo tanto de coste, que supone el no tener que esperar a ver si algo sucede y hacer que suceda, más aún hablando de documentales de naturaleza, es otra de las ventajas del modelo Cousteau, sobre todo si se trabaja para la televisión, donde la necesidad de programas es mayor y el tiempo de realización y montaje es reducido en comparación con los trabajos cinematográficos. 


\section{National Geographic y Walt Disney: necesariamente entretenidos}

A partir de 1961, la división televisiva de National Geographic Society empieza a producir documentales sobre naturaleza para que sean emitidos en televisión. Los nuevos programas tienen buenas audiencias, lo cual demuestra que los programas científicos también pueden interesar a un público amplio no familiarizado con este tipo de contenidos y, por lo tanto, se pueden convertir en productos audiovisuales rentables. El éxito de estos nuevos formatos se basa en una doble selección. Primero, se elige preferentemente a aquellos animales que resulten a priori atractivos para la audiencia, en su mayoría este grupo lo componen los depredadores más conocidos como el león, el tigre, el tiburón, etc. Y segundo, se opta solo por las imágenes espectaculares, lo que se llama imágenes de "gran impacto" (LEÓN, 1999: 88) que pudieran sorprender a los espectadores, porque su gran fuerza visual y porque nunca antes se habían visto. $\mathrm{Na}$ tional Geographic revoluciona el formato de documental de divulgación científica al romper con la decepción del síndrome del zoo, lugar donde habitan animales exóticos, pero privados de su entorno salvaje y del tipo de vida natural que desarrollan allí, donde los animales no ejecutan ninguna de las acciones que los hacen singulares, sorprendentes y, por lo tanto, también divertidos.

Pero hay otro gran referente de los documentales naturaleza que buscan ser cada vez más entretenidos para el espectador: Walt Disney. Basta con explicar que Walt Disney se paseaba por todos los zoos de Europa, e incluso llegó a comprar animales, como 4 diminutos asnos de Cerdeña, para buscar ideas que sumar a su proyecto de parque de atracciones (THOмAs, 1995: 269-270) para entender que las películas de la naturaleza que hacía la factoría Disney no pretendían ser científicas o justas con la realidad, sino entretener al mayor número de personas posible y transmitir la idea de una naturaleza como un paraíso de pureza y armonía. Desde Bambi (1942), el primer largometraje de animación centrado en la vida de un animal salvaje, hasta la serie de cortometrajes documentales True-Life Adventures (1948-1960), en la que es raro ver a un depredador matando a una presa, Disney crea una ensoñación de la naturaleza, un lugar diseñado sin conflictos y sin muerte, controlado como si fuera una atracción de feria. En principio, un pésimo ejemplo como documental científico (FrANCÉs, 2010: web).

Por el contrario, la nueva línea de documentales de naturaleza (Nature, Wild Kingdom, Wild America, National Geographic Explorer, The undersea world of Jacques Cousteau o El Hombre y la Tierra) buscan una representación de la naturaleza más completa y real, y eso implica quitarle todos los velos de excesiva dulzura o amaneramiento infantil que pudieran contener la representación naive de la vida animal que hacía Disney en sus productos. Margaret KING insiste en que la naturaleza que aparecía en las películas de Disney no era el reflejo de un ecosistema, sino de un "ego-sistema", porque se veía a los animales a través del tamiz del ser humano que volcaba sus valores en tres niveles: antropomorfización, sentimentalismo y moralismo (KING, 1996: 62).

Los nuevos programas científicos ponen límites a esta representación de la naturaleza, pero como productos televisivos no puede evitar un condicionante: divertir. Antes de la aparición de la televisión, los documentales declaradamente educativos ya 
buscaban fórmulas para atraer al público sin necesidad de dejar de cumplir su función. En la República se exhibieron en salas cintas de divulgación zoológica con cierta tendencia a la antropormorfización ya en los títulos: Los aristocráticos del reino animal (1933), El rey de los animales y su familia (1933), La abeja y su reinado (1935) (PAZ y CABEZA, 2010: 760). La televisión hace un recorrido similar. Al principio de los años 50, las audiencias de televisión son millonarias y superan en mucho el número de espectadores que van al cine (KING, 2000: 228): la televisión se convierte en el nuevo entretenimiento de masas. Progresivamente, los programas que tienen un interés puramente educativo empiezan a desaparecer o a adecuarse a las exigencias comerciales, lo cual significa que tienen un doble objetivo (enseñar y entretener) y, por lo tanto, deben cambiar su formato. Como medio de masas ya consolidado, la finalidad de la televisión, incluso en sus espacios científicos o educativos, tiene que ser entretener. Si un programa quiere mostrar la realidad científica, tiene que hacerlo adaptándola a las exigencias de un medio audiovisual y a su finalidad de divertimento. Y ahí es donde la fórmula Disney no se rechaza, sino que se imita, al menos en sus planteamientos narrativos. En True-Life Adventure se aplica con éxito la necesidad de un control de los contenidos para que evolucionen en un in crescendo narrativo y se introducen toda una serie de recursos como la dualidad ternura/violencia, la idea de personaje o protagonista, la música para definir situaciones o expresar supuestos sentimientos de los animales, la cámara lenta, la variación de planos dentro de la misma escena... (SALCEDO, 2008: 75)

La naturaleza se condensa y edita para dar a conocer al espectador la vida de los animales salvajes en forma de "titulares", como si hubiera que comprimir lo más excitante de una noticia en una línea para despertar el deseo del espectador por continuar leyendo. Esos "titulares" son excitantes: siempre hay mucho peligro y todo suena a aventura. No hay que olvidar que los productores de los mejores proyectos de Disney sobre la naturaleza -James Algar, Winston Hibler, Harry Tytle, Ken Peterson y Ben Sharpsteen- provenían de las películas de dibujos animados donde cada fotograma de la película estaba sometido a un único aspecto: el guión (KING, 1996: 63)

Rodríguez de la Fuente, igual que otros autores, conoce y asume la obligación de crear entretenimiento, más allá del tipo de programa que desees hacer:

"Yo siempre quiero enviar un mensaje científico con un lenguaje que pueda comprender todo el mundo. Yo no puedo olvidar que hago programas para la gente, que no hago programas para los sabios, ni para los investigadores, ni siquiera para los críticos. Yo hago programas para el hombre medio, para la persona que es profana en las Ciencias Naturales y que por consiguiente hay que darle las cosas de tal manera que le guste, que les agrade, que le resulte tan gratas como le puede resultar las películas de ciencia ficción o una película de policías" (SALCEDO, 2008: 237)

La referencia a las películas no es casual, ni tampoco extraña en los documentales de divulgación científica. Attenborough también incide en que los mejores programas son como historias y los compara con "una novela de detectives" (LEÓN, 1999: 123) por cómo se une el material en torno a una trama y por el deseo del espectador por no dejar de mirar mientras es conducido narrativamente hasta un desenlace. Pero Rodríguez de la Fuente amplía la metáfora: efectivamente las películas son historias, pero 
con imágenes, y éstas son el paso previo y necesario, la materia prima a través de la cual se construye y se relata. Pero, ¿cómo conseguir esas imágenes? En principio, y por su experiencia en la serie Planeta Azul (1970-74), sabe que la tarea no resulta nada fácil. En el capítulo titulado Los mensajeros de la paz, el uso didáctico que quiere hacer Rodríguez de la Fuente de los documentales científicos queda limitado porque las imágenes no captan lo que él necesita, lo que le fuerza a utilizar recursos expresivos poco audiovisuales. Por ejemplo, se informa al telespectador de la composición de la dieta del cernícalo de forma exclusivamente escrita: a través de porcentajes y gráficos. La falta de imágenes no se puede esconder. Un $72 \%$ de la dieta de este ave está compuesta por roedores, pero no se ve ninguna escena de caza del animal. Es más cuando está alimentado a sus polluelos, el documentalista se ve obligado a adivinar más que a contar: "seguramente se estarán comiendo un ratoncillo", dice. Igualmente, Rodríguez de la Fuente usa un dibujo para explicar por qué el cernícalo recibe ese nombre debido a la manera en la que se "cierne" desde el aire sobre sus presas: nuevamente no hay ninguna imagen en la que se aprecien los movimientos del cernícalo en todo el documental. Y la situación se repite con otras aves, es decir, la acción de Cazar, el momento más espectacular y dramático de todos los que pueden obtenerse, queda fuera de las filmaciones y se ven instantes de antes (lanzándose al agua) o de después (el ave tiene un pez en el pico). Por el contrario hay 5 escenas en las que diferentes aves (alcaraván, becada, cernícalo, alcaudón) dan de comer a sus polluelos. También hay 2 escenas en las que se filma la incubación de los huevos. En cuanto a planos relacionados con la acción de Comer, la aportación es escasa: un Piti Tuerto extrayendo piñones y una ardilla comiendo. El documental que comenta Rodríguez de la Fuente tiene importantes lagunas visuales, porque apenas se reflejan acciones de los animales y las que aparecen no son una selección buscada, no son las mejores, sino las que se filman con mayor comodidad, como la alimentación de los polluelos que se resuelve con una cámara fija apostada cerca del nido en una época concreta.

Si Rodríguez de la Fuente quería utilizar historias como medio para transmitir el conocimiento científico, y ser tan entretenido como una película de Disney, necesitaba imágenes buenas y pertinentes, que contaran la verdad científica y que no sirvieran sólo como ilustración mientras una voz en off decía lo mismo que se puede leer en cualquier libro. El desafío era enorme, como se comprobó en el rodaje de Venezuela.

\section{El montaje del jaguar: creando la realidad}

La Serie Venezolana de El Hombre y la Tierra se emitió en el primetime de los viernes, aunque luego el horario en la parrilla televisiva fue variando. Rodríguez de la Fuente y su equipo se enfrentaban a su primera experiencia en rodajes con equipos cinematográficos. Trabajar en cine significaba que tendrían poco tiempo de exposición para conseguir momentos espectaculares, dada la imposibilidad de desperdiciar mucho metraje por el alto coste que esto supondría y por el escaso tiempo que disponían para estar en Venezuela: 2 meses. En previsión de estos límites, el naturalista deseaba contar con tomas de cobertura, como los directores de ficción, y otros múltiples recursos que le permitieran salvar en postproducción todas las dificultades que le creara la realidad: 
"Pidió, tanto en los rodajes de Venezuela, como después en España, llevar en su equipo a los mejores profesionales; recursos para construir platós y rodar al natural en el campo; medios para capturar animales o trasladar otros ya cautivos desde zoos, y mantenerlos en semilibertad para filmar primeros planos con detalle, así como escenas de predación, de modo que pudiera combinar esas tomas con las rodadas en libertad [...] (VARILLAS, 2010: 547-548).

El rodaje le dio la razón, sobre todo, en relación a uno de los objetivos más codiciados por el equipo: filmar al jaguar. Solamente uno de los 9 episodios de la Serie Venezolana trata específicamente sobre el jaguar (El mundo del jaguar). En los otros 8 capítulos no se hace ninguna referencia directa en su título al jaguar, ${ }^{1}$ pero aún así el depredador siempre está allí. La mayoría del tiempo que el jaguar está en imágenes resulta poco espectacular: 11 veces aparece simplemente andando, moviéndose por la selva y en otras 7 ocasiones se ve como bebe o se revuelca en el suelo (retozar). El jaguar también aparece comiendo una presa en 5 oportunidades, lo cual, sin duda, es más atractivo visualmente que lo anterior. Aún así, moverse, beber, retozar o comer son acciones que el espectador puede llegar a ver en un zoo que tenga jaguares o depredadores parecidos, lo que significa que un $71 \%$ de las apariciones del tigre americano en la serie documental de El Hombre y la Tierra se pueden considerar poco novedosas y no añaden mucho valor al producto audiovisual. El otro $29 \%$ de las apariciones del jaguar está centrado en dos acciones especialmente seductoras para la audiencia, porque en ningún otro sitio, ni en zoos ni en circos, se podía ver algo igual: luchar $(6 \%)$ y cazar $(22 \%)$. Frente a las 11 veces que el jaguar aparece andando sólo hay 2 ocasiones en las que se muestran escenas de lucha y, en realidad, es sólo una porque está repetida: el jaguar se enfrenta contra el mismo báquiro en El Hombre y la Tierra (19:59) y en El mundo del jaguar (15:41).

Cuadro 2. Las acciones del jaguar en El Hombre y la Tierra. Serie Venezolana

\begin{tabular}{|l|}
\hline VER (andar, correr, estar tumbado) \\
\hline El mundo del jaguar $(6: 23)$ \\
\hline El mundo del jaguar $(7.25)$ \\
\hline El mundo del jaguar $(14: 14)$ \\
\hline El mundo del jaguar $(14: 56)$ \\
\hline El mundo del jaguar $(16: 45)$ \\
\hline Un campamento en la selva virgen $(3: 36)$ \\
\hline Mi amiga la nutria $(17: 29)$ \\
\hline Mi amiga la nutria $(18: 51)$ \\
\hline La nutria gigante sudamericana $(9: 44)$ \\
\hline La nutria gigante sudamericana $(11: 42)$ \\
\hline La nutria gigante sudamericana $(20: 46)$ \\
\hline
\end{tabular}

${ }^{1}$ Los 8 capítulos son El rodeo de los Chigüires, El hombre y la tierra, Los llanos de Venezuela, Mi amiga la nutria, La nutria gigante sudamericana, Un campamento en la selva virgen, La selva virgen venezolana y Operación Anaconda. 


\begin{tabular}{|l|}
\hline LUCHAR \\
\hline El Hombre y la Tierra (19:59) [Báquiro] \\
\hline El mundo del jaguar (15:41) [Báquiro] \\
\hline HACER \\
\hline Operación Anaconda (6:30). Retozar \\
\hline El mundo del jaguar (4:58). Retozar \\
\hline El mundo del jaguar (22:21). Beber \\
\hline Un campamento en la selva virgen (15:00). Marcar el territorio orinando y retozar \\
\hline Mi amiga la nutria (18:23). Beber \\
\hline La nutria gigante sudamericana (10:56). Beber \\
\hline La nutria gigante sudamericana (16:10). Beber \\
\hline CAZAR \\
\hline El rodeo de los chigüires $(9: 46)$ [Perezoso] \\
\hline Operación Anaconda (4:43) [Cervatillo] \\
\hline El mundo del jaguar (21:04) [Ciervo] \\
\hline La selva virgen venezolana (14:26) [Mono] \\
\hline La selva virgen venezolana (24:23) [Perezoso] \\
\hline La nutria gigante sudamericana (21:51) [Tortuga] \\
\hline La nutria gigante sudamericana (15:00) [Caiman] \\
\hline COMER \\
\hline Los llanos de Venezuela (17:06) \\
\hline La selva virgen venezolana (15:56) \\
\hline Operación Anaconda (5:59) \\
\hline El mundo del jaguar (23:53) \\
\hline La nutria gigante sudamericana (16:56) \\
\hline
\end{tabular}

Fuente: Elaboración propia. El Hombre y la Tierra. Serie Venezolana

En cuanto a los momentos de caza, sin duda de los más esperados por los espectadores, el equipo de El Hombre y la Tierra tiene problemas para filmarlos. La captura de un pequeño caimán es la única escena que aparece limpia y completa, sin que haya dudas de que el montaje arregla o parchea la realidad. También hay un fallido intento de caza: el jaguar intenta comerse una tortuga, pero después de algunos rodeos y zarpazos, desiste. Por otro lado, las cámaras tienen problemas para filmar el momento de la caza en dos ocasiones. En El mundo del jaguar (21:4) se ve como el depredador lanza su ataque contra un ciervo, pero no queda filmado justo el momento en el que cae sobre la presa. Hay un mínimo corte en montaje y luego se ve como ya tiene apresado al ciervo por el cuello, mientras el animal pugna por liberarse. La cámara registra el antes y el después, pero no el instante más importante de todos. Algo 
similar sucede con la captura de un mono en La selva virgen. En un plano general se ve como el jaguar salta para capturar su presa y falla, el mono busca protección en las ramas más altas de un pequeño y frágil árbol, mientras el depredador continúa agitando el árbol para que caiga el mono. Al final, si nos fiamos de cómo se gira el jaguar al percibir el movimiento del mono, la presa parece que cae, pero no se ve. El jaguar salta al suelo detrás y ahí hay un corte, una elipsis temporal breve que no permite ver uno de los momentos más poderosos en términos dramáticos. Tras el corte, el siguiente plano muestra al depredador en el suelo con el mono ya atrapado y sujeto. El primer y supremo instante de la captura no se filmó.

En las demás escenas de caza también se aprecian problemas en el rodaje para lograr las imágenes adecuadas, y es el montaje el que tiene que contar la historia que no se puede filmar al completo, sino por fragmentos. En El mundo del jaguar, cuando el jaguar se supone que está acechando al ciervo, un pequeño detalle revela un fallo de raccord: el felino tiene manchada la pata izquierda de sangre. En el momento de iniciar la carrera para atacar (21: 8), esa misma pata izquierda está inmaculada, sin mancha ninguna. Así, en la sala de montaje se sitúa antes de la caza unas imágenes que, en realidad, se producen después de la captura. Mientras el jaguar devora al ciervo, apoya el cuello del animal sobre su pata izquierda y se mancha (23: 59 - 24: 18). Un poco después, el mismo jaguar se relame las patas, también manchadas de sangre (24: 19). El jaguar pasea por la selva después de haber matado al ciervo, al menos eso es lo que nos dice la imagen, pero la voz en off la contradice e impone un sentido ajeno: construye la ilusión de que el depredador está a solo unos segundos de intentar hacerse con su presa. Hay una dislocación temporal de las imágenes en el montaje para beneficio de una mayor coherencia del relato. Rodríguez de la Fuente puede crear suspense: "Cuando caza ciervos. El tigre camina muy despacio. Espera sorprender [...]" (20: 21 - 20: 27). Las imágenes del jaguar paseando por la selva tenían más valor narrativo al principio para decir que el jaguar estaba acechando que al final para decir que el jaguar estaba satisfecho después de comerse el ciervo. El montaje decide su sentido.

Lo mismo sucede en Operación Anaconda. Esta vez la presa es un cervatillo y el montaje se sirve de diversas imágenes de animales en acción, que por sí mismas son muy polisémicas (un animal que se va, otro que se desplaza o que se alerta ante un ruido nuevo), para integrarlas en la construcción de un único sentido: hay peligro por la presencia de un jaguar (Ver Cuadro 3). El guión de Rodríguez de la Fuente ancla uno de los muchos significados posibles que tendrían las acciones que se ven.

Cuadro 3. Montaje de un jaguar acechando a un cervatillo (Operación Anaconda)

\begin{tabular}{|c|l|}
\hline Voz en off & Imágenes \\
\hline "El jaguar, el más poderoso y grande de los & \\
gatos sudamericanos. Es observado por todo & \\
el mundo arbolícola. El mono araña le mira & Un loro está en un árbol. \\
con desconfianza y avisa a sus congéneres" & El jaguar anda por la selva. \\
"Busca una posición más segura en las ramas & El mono araña trepa por un árbol. \\
más finas de un árbol porque el tigre no ha & \\
cazado esa noche" & \\
\hline
\end{tabular}




\begin{tabular}{|c|c|}
\hline $\begin{array}{l}\text { "Busca una presa nueva. Y todo el mundo lo } \\
\text { sabe en la selva. Cuando el tigre camina es- } \\
\text { condido Cuando la Taira le observa desde su } \\
\text { árbol pasando por el claro, la gente de la } \\
\text { selva, los animales del bosque de galería co- } \\
\text { nocen que la muerte ronda próxima" }\end{array}$ & La taira está en una rama y mira hacia abajo \\
\hline $\begin{array}{l}\text { "La pareja de jóvenes coatíes también descu- } \\
\text { bren a tiempo al tigre. El tigre no tiene prisa. } \\
\text { Encontrará su presa. }\end{array}$ & La pareja de coatíes miran hacia abajo. \\
\hline $\begin{array}{l}\text { "El pécari, uno de los animales más resistentes } \\
\text { y agresivos contra los depredadores está } \\
\text { oliendo el tufo de la fiera" }\end{array}$ & El pécari está quieto en medio de un claro. \\
\hline $\begin{array}{l}\text { "El enorme tapir intuye que se acerca el peli- } \\
\text { gro" }\end{array}$ & $\begin{array}{l}\text { El tapir están andando, pero se detiene en seco } \\
\text { y se queda parado. }\end{array}$ \\
\hline "Y el venado" & $\begin{array}{l}\text { Un venado levanta la cabeza como si hubiera } \\
\text { escuchado algo. Está en alerta. }\end{array}$ \\
\hline $\begin{array}{l}\text { "El tigre avanza lentamente. Sus presuntas pre- } \\
\text { sas van huyendo. Rompen el monte y salen } \\
\text { de sus encames" }\end{array}$ & $\begin{array}{l}\text { Un tapir corre. } \\
\text { El pécari corre. } \\
\text { El ciervo sale de entre unas pajas, amoldadas a } \\
\text { su cuerpo. }\end{array}$ \\
\hline $\begin{array}{l}\text { "Pero encontrará una presa fácil, distraída. Sin } \\
\text { experiencia" }\end{array}$ & $\begin{array}{l}\text { Un cervatillo solitario se vuelve y le vemos de } \\
\text { cara. }\end{array}$ \\
\hline
\end{tabular}

Fuente: Elaboración propia. El Hombre y la Tierra. Serie Venezolana

En Operación Anaconda se vuelve a reproducir el problema de filmar escenas de caza en la naturaleza: una historia con grandes expectativas visuales no dispone de las imágenes que de hecho la cuenten. Hay también un fallo de raccord que descubre el trabajo de montaje. El cervatillo está solo en un plano corto y cerrado (4: 34). Es la primera vez que aparece. Apenas se puede ver el entorno en el que se encuentra, pero se puede deducir que no tiene nada que ver con el lugar donde unos segundos después se supone que es cazado. El cervatillo está sobre una pequeña loma de tierra, en la que se ven algunas hojas secas, pero en la que prima la imagen de una superficie compacta. En el minuto 4:43, cuando se desencadena el ataque del jaguar, el cervatillo está justo en el medio de un pequeño claro, no invadido por el follaje de la selva, y el suelo está formado por hojarasca y espadañas secas, que están por todos los sitios y que no aparecían en el plano en el que el cervatillo estaba solo. La presa está en el centro del plano y el jaguar aparece de improviso por la derecha, como una exhalación. El plano decisivo llega en medio de la acción. Cuando ya el jaguar ha iniciado el ataque. Apenas da tiempo a verlo, aunque esta vez sí se aprecia claramente el primer instante de la captura, incluso, y sorprendentemente dada la velocidad y lo inesperado de la acción, hay dos tiros de cámara diferentes y simultáneos que rueda la misma acción, lo que significa que había dos cámara perfectamente apostadas para filmar lo mismo desde dos puntos de vista diferente.

Luego, en la acción de comerse al cervatillo, el montaje tiene que intervenir otra vez para consolidar la historia. Lo que vemos que se come el jaguar no es el cervati- 
llo de Operación Anaconda, sino el ciervo de El mundo del jaguar, o viceversa. Esta escena ha sido cuidadosamente fragmentada para no repetir exactamente el mismo plano; primero aparece un plano corto en el que el jaguar devora al ciervo sobre una pata (24:02 - 24:17), la misma pata que aparecerá luego manchada en El mundo del jaguar y, en segundo lugar (24:18 - 24:23), también repite un plano, un encuadre idéntico, que usa en El mundo del jaguar, la única variación es que continúa donde terminó el plano en el otro episodio: se aprovecha la misma acción en dos capítulos distintos.

Las reconstrucciones no terminan ahí. En la escena de la captura del perezoso ( $L a$ selva virgen venezolana) hay un buen final: un jaguar trepa a un árbol pequeño y atrapa a un perezoso. En teoría, lo que se ve en imágenes, "más elocuentes que todos los relatos", como recuerda la voz en off, es que el perezoso se cambió de árbol, pero cuando estaba encaramándose a la parte más alta y segura rompió una rama sin querer y el ruido delató su posición. El jaguar había pasado por allí sin intuir su presencia, pero el error del perezoso hace que el depredador regrese y lo capture. Esta pequeña y espectacular historia se cuenta con imágenes de otros momentos y otros perezosos, pero en la sala de montaje se construye como una única historia y así llega a los espectadores. Sin embargo, nuevamente los fallos de raccord desvelan la dinámica del montaje:

1. Hay hasta 3 perezosos diferentes. Primero, un perezoso desciende por un árbol con una forma rectilínea, casi como un mástil. Cuando el perezoso se traslada de un árbol a otro ya es otro individuo (se observa en el pelaje) y otro árbol. Por último, este segundo perezoso se traslada de un árbol que tiene un grosor algo mayor al de un vaso a otro bastante semejante. Los dos están colocados casi en forma de "V", aunque no llegan a tocarse, están muy próximos el uno del otro. Cuando nos situamos en el plano general en el que el jaguar atrapa al perezoso no existe el primer árbol y la morfología e inclinación del tronco del segundo árbol es diferente. El jaguar captura así al tercer perezoso.

2. Cuando el perezoso rompe la rama, ésta queda vencida, pero no se desprende del árbol, sino que se queda colgando con sus grandes hojas verdes (plano corto). Esa rama no existe en el plano general en el que ataca el jaguar.

3. Los tamaños de los perezosos son diferentes, sobre todo, el del último, el que sucumbe ante el jaguar, mucho menor que sus congéneres.

Si de verdad todo hubiera sucedido como se quiere hacer creer en el montaje, el plano más apropiado para filmarlo hubiera sido un plano secuencia fijo y general. Esto supondría perder los planos cortos o planos detalles en los que se apreciaría la fractura de la rama, pero eso no impediría que el espectador viera de hecho que la rama se rompe. Simplemente avisándolo la voz en off y ver cómo levemente el perezoso pierde su apoyo hubiera sido suficiente para hacer verosímil la acción de romper una rama. Incluso si el jaguar en un momento estuviera en fuera de campo no tendría ninguna importancia, porque al romperse la rama y desequilibrarse el perezoso, inmediatamente veríamos el regreso del jaguar al plano, lo cual incluso tendría más fuerza dramática que si fuera encuadrado en todo momento. Por lo tanto, la escena del jaguar y el perezoso es una recreación o reconstrucción de la realidad. A tra- 
vés del montaje se intenta recuperar mediante un rompecabezas de imágenes algo que sucede en la selva, pero que es complicadísimo filmar en directo cuando ocurre. Un jaguar no está buscando sistemáticamente por los árboles para encontrar un perezoso, sino que lo descubre cuando éste hace algún movimiento en falso que delata su posición. Eso es lo que sucede en la naturaleza. El equipo de El Hombre y la Tierra filmó el final (la captura de un perezoso) y luego intentó recomponer lo que visualmente faltaba para tener la historia completa. Es más, en este caso, el hecho de tener filmado en plano corto el momento en que un perezoso rompe una rama da mayor potencia visual a la explicación de que un movimiento en falso del perezoso le puede costar la muerte. Narrativamente, el suceso de la rama es más útil que un movimiento a destiempo o el traslado del perezoso de un árbol a otro, porque simboliza de forma muy visual el error del animal.

En El mundo del jaguar, el trabajo de montaje va más allá y llega a reconstruir totalmente una escena de caza entre el jaguar y el tapir que nunca existió. Un tapir empieza a correr por la selva y un jaguar también, pero son escenas distintas que ocurren en tiempos y lugares diferentes. En el montaje aparecen unidas por la voz en off, que también decide cuando termina la persecución. El tapir se mete en una pequeña laguna y el jaguar anda por la selva y, de pronto, se da la vuelta en sentido contrario. La traducción que hace el guión de Rodríguez de la Fuente de estas dos acciones empalmadas una detrás de otra es la siguiente: "[en la laguna] nunca osaría el tigre en intentar darle caza, porque el tapir bucea perfectamente y escaparía del ataque del gran cazador en las aguas profundas de la laguna de la selva" (8: 37 - 8: 50).

\section{Conclusión y reflexión}

La representación que se hace en los 18 capítulos de la Serie Venezolana de la vida del jaguar en la naturaleza deja algunas reflexiones. Rodríguez de la Fuente tiene menos imágenes de acción de las que necesitaría tener, como prueban las repeticiones de varias escenas (báquiro y perezoso), la recreación del intento de caza de un tapir, que nunca existió, pero que se representa como cierta, y el decisivo trabajo de montaje en las escenas más espectaculares que se reconstruyen a partir de momentos y animales diferentes. El equipo de El hombre y la Tierra logra filmar algunas imágenes de gran impacto, pero a veces no son de calidad y otras no son suficientes para crear historias completas, con principio, medio y fin, y responder así al doble deseo de la audiencia de conocer la naturaleza y ver un producto audiovisual entretenido.

En definitiva, a través del jaguar y de la filmación en Venezuela, Rodríguez de la Fuente comprueba directamente en un rodaje lo que ya conocía por el material audiovisual que emitía en Planeta Azul: la cámara, en la mayoría de los casos, no está presente cuando suceden los momentos más espectaculares, desconocidos y significativos de la vida de un animal en estado salvaje. El documental de naturaleza adolece del mismo problema que cualquier otro tipo de documental: no estar filmando en el momento en el que la realidad debería ser filmada para producir una buena película. No es algo nuevo. BARNOUW habla de las primeras "reconstituciones" ya en las piezas documentales de principios del siglo XX, y subraya la falta de preocupación del público sobre el vínculo que tuviera esa escenificación con la realidad en la que su- 
puestamente se inspiraba (BARNOUw, 2005: 28-30)2. Ni los productores ni los espectadores tenían dilemas epistemológicos al respecto. En aquellas "reconstituciones" o reconstrucciones el espectáculo estaba por encima de la verdad, y así fue en gran medida hasta que llegó Flaherty y su Nanook, el esquimal (1922).

Flaherty convence a Nanook de que lo primero es el aggie (la película) -aunque en verdad lo primero es el espectador que ve la película-, y por ella le empuja a construir un iglú más grande de lo normal para introducir la cámara y filmar lo que sucedía allí como si de hecho fuera su propio iglú. En verdad no era un iglú, sino un set de grabación, o más bien las dos cosas: Nanook y su familia simulaban que vivían en medio iglú como si estuviera entero, mientras Flaherty filmaba al aire libre (PAZ y MONTERO, 1999: 101). El documentalista también consiguió que varios esquimales accedieran a cazar morsas según el estilo de caza tradicional, lo cual implicó que, en medio de la filmación, Flaherty se negara a usar su escopeta para matar a una morsa, y ayudar así a los esquimales que se estaban jugando la vida para no caer al agua y cobrarse la pieza que habían cazado con arpón. No podía aparecer un disparo, porque en la realidad de la caza con arpón no había disparos (BARNouw, 2005: 38). Nanook, el esquimal no muestra la vida de un esquimal, reconstruye la vida de un esquimal. Aquí la verdad y el espectáculo (la película bella) igualan fuerzas, y lo más importante es que se traspasa un límite conceptual: si no estabas cuando sucedió lo que deseas filmar, aún tienes una segunda oportunidad. La solución que dio Flaherty estaba en profundizar en el arte del montaje, en conseguir que la realidad que se construye en una sala sea tan válida como la "auténtica".

Algunos años después, Joris Ivens (The Spanish Earth, 1937) y los documentalistas de Frontier Films (Native Land, 1934-1937) recurrieron a actores y al guión para recuperar la realidad que no llegaron a tiempo a filmar. Algunos pensaron que eso era ir demasiado lejos, que era ficción, luego mentira. Ivens insistía en la legitimidad de recomponer esa realidad y ofrecérsela al espectador como verdad y, por supuesto, deseaba terminar con la polémica sobre si eso significaba en alguna medida intervenir o crear la realidad. Para el director holandés la sola presencia de una cámara en cualquier lugar ya significaba un condicionante, una intervención, un cambio:

"If persons opposed to re-enacted scenes consider the fact truthfully that everything must be filmed just as it is, just as it happens, then our films would show people constantly staring into the camera, because that is what really happens when you photograph people and that would be the truth, at least according to our opponents. So can we say that re-enactment starts with the interference of the director or cameraman into the "natural" behaviour of people by insisting that they "do not look into the camera" (IVENS, 1953: 265).

Otros autores ampliaron la idea de la reconstrucción y decidieron que no necesitaban reproducir exactamente lo que pasó, bastaba con hablar de ello para arrastrarlo al tiempo natural de lo cinematográfico: el presente. En Encuesta sobre el amor (Pier Paolo Pasolini, 1965) y en Bowling for Columbine (Michael Moore, 2002) se usa la entrevista para relatar partes de la realidad que o no se podían ver (relaciones sexuales o cortejos en el caso de Passolini) o que no hubo tiempo ni oportunidad para fil-

2 BARnouw, Erik, El documental. Historia y estilo, Gedisa, Barcelona, 2005, pp. 28-30. 
marlo. Pasolini y Moore conducen -incluso manipulan- al entrevistado para que cuente y valore lo que pasó como ellos desean que lo cuente y lo valore según lo que creen que sucedió. Los documentalistas se convierten así en pintores del realismo que quieren anularse como intermediarios, sin que esto sea posible. Y curiosamente esas conversaciones son suficientes para dar por vista la realidad. En Grizzly man (Werner Herzog, 2005) se opta por una audaz solución intermedia entre una entrevista y una reconstrucción. Algunos de sus testimonios actúan como si fueran cuentacuentos para niños y fuerzan al máximo su gestualidad para reproducir una situación que vivieron y que el realizador no pudo filmar: un personaje se esconde entre unos arbustos, como hizo el día que vio a un oso atacando al protagonista, Timothy Treadwell; un forense explica como estudió el cuerpo de Treadwell con tanta exageración que hace que el espectador se pregunte si es un forense o un mal actor que hace de forense... En resumen, muchos cineastas se han encontrado con la necesidad y el problema de contar sucesos o acciones que no pudieron filmar, y la solución fue siempre la reconstrucción en diferentes modalidades.

En Venezuela, Rodríguez de la Fuente se halló ante la misma realidad huidiza y evanescente que muchos otros autores, y también tuvo que encontrar la mejor manera posible de reconstruirla para la televisión. Se puede concluir que en esta primera serie de El Hombre y la Tierra, el naturalista confirma algo que ya conocía, pero no como problema de producción real: la incapacidad de filmar lo más interesante de la vida de un animal salvaje. Sólo en el montaje y en postproducción consigue hacer aparecer una realidad que nunca pudo filmar. El director de El Hombre y la Tierra comprueba por sí mismo que el rodaje al aire libre, y sin control de los animales, puede suponer el fracaso de la serie televisiva como producto audiovisual. No hay duda de que es imposible conseguir algunas de las imágenes más espectaculares, significativas y recordadas que se obtuvieron posteriomente en la Serie Ibérica, si no fuera por la utilización de animales impregnados (cormoranes, halcones, águilas, lobos...), que se habían criado con el hombre y estaban acostumbrados a dejarse dirigir por éste. Luego, el montaje haría el resto. Rodríguez de la Fuente no hizo otra cosa que dar la razón a Flaherty e intentó recuperar la realidad de la forma más fiel y exacta que le fue posible, porque no hay que olvidar que para todo documentalista lo más importante es el "aggie" y la verdad que contiene.

\section{Referencias bibliográficas}

AITKEN, Ian (editor) (2006): Encyclopedia of the Documentary Film. Vol. 1 A-G. New York, Routledge.

ARAUJO, Joaquín (1990): Felix Rodríguez de la Fuente. La voz de la naturaleza. Barcelona, Salvat.

BARNOUW, Erik (2005): El documental. Historia y estilo. Barcelona, Gedisa.

FRANCÉS I DOMÉNECH, Miquel (2002): "Los documentales de naturaleza ayer y hoy. Realidad versus virtualidad". Telos, $\mathrm{n}^{\mathrm{o}} 52$. $2^{\mathrm{a}}$ época, pp. 17-21. http://sociedadinformacion.fundacion.telefonica.com/telos/articuloperspectiva.asp@idarticulo $=3 \&$ rev $=52 . h t m$ [Fecha de consulta: 28 de julio de 2011] 
IVENS, Joris (1953): "Repeated and organized scenes in documentary film", en BAKKER, K. (editor) (1999): Joris Ivens and the documentary context, Amsterdam: Amsterdam University Press, pp. 265-266.

KING, Kenneth P. (2000): "Educational television: Let's explore Science". Journal of Science Education and Technology, vol. 9, n 3, pp. 227-246.

KING, Margaret J. (1996): "The audience in the wilderness: The Disney nature films". Journal of Popular Film \& Television, vol. 24, nº 2, pp. 60-69.

LEÓN, Bienvenido (1999): El documental de divulgación científica. Barcelona, Paidós.

PAZ, María Antonia y CABEZA, José (2010): "La realidad que vieron los españoles. El cine de no ficción durante la Segunda República (1931-1936)". Hispania, vol 7, no 236, pp. 737-764.

PAZ, María Antonia y MONTERO, Julio (1999): Creando la realidad. El cine informativo 1895-1945. Barcelona, Ariel.

POU VÁZQUEZ, Miguel (1995): Félix Rodríguez de la Fuente. El hombre y su obra. Barcelona, Planeta.

SALCEDO DE PRADO, Miriam (2008): El documental de divulgación cientifica sobre la naturaleza: técnicas narrativo-dramáticas y retóricas empleadas por Félix Rodríguez de la Fuente en El Hombre y la Tierra, (tesis doctoral). Pamplona, Universidad de Navarra.

SÁNCHEZ-ESCALONILLA, Antonio (2004): Estrategias de guión cinematográfico. Barcelona, Ariel.

THOMAS, Bob (1995): Walt Disney. Personaje inimitable. Madrid, Iberonet.

VARILLAS, Benigno (2010): Féliz Rodríguez de la Fuente. Su vida, mensaje de futuro. Madrid, La esfera de los libros. 